\title{
FACTORS OF CHINESE RESIDENTS' UNPAID WORKING TIME AND ITS GENDER DIFFERENCE: A MULTIPLE REGRESSIONSTUDY
}

\author{
Tang Anqi \\ Ginling College, Nanjing Normal University, Nanjing 210097, China \\ DOI: 10.46609/IJSSER.2021.v06i03.006 URL: https://doi.org/10.46609/IJSSER.2021.v06i03.006
}

\begin{abstract}
The paper examines what factors have impact on Chinese residents 'unpaid working time and its gender difference. Unpaid working hours refer to the working time that residents do not work for the purpose of labor remuneration. To a certain extent, the length of unpaid working time reflects the quality of life and social fairness of residents. Among all the studies on unpaid labor, the gender difference in the length of unpaid labor time is a topic worthy of attention. Unfair problems within the family are easily caused because of imbalance distribution of unpaid labor time between the family members. Especially in the case of double worker families, the gap between paid working hours and income between the two sexes has narrowed, but there is still a large gap between unpaid working hours. Much housework is undertaken by women, which is not conducive to improving women's happiness. Studies have shown that women spend significantly more time in unpaid labor than men, but we still don't know which factors will expand or narrow the difference. In order to answer this question, this paper uses the data of China General Social Survey in 2015 (CGSS) to conduct a multivariate regression analysis. The paper reveals that the factors influencing the unpaid working hours between both male and female have a strong heterogeneity. Marriage significantly improves the unpaid working hours of women, but shortens the unpaid working hours of men; gender equality attitude has a significant impact on reducing the unpaid working hours of women However, it has no significant effect on male's unpaid labor participation time.
\end{abstract}

Key words: unpaid working time; gender attitude; gender difference

\section{INTRODUCTION}

The discussions of unpaid labor take its rise in 1992. Devereux \& Locay (1992) first put forward the concept of unpaid labor of residents, and constructed a theoretical model to measure and evaluate the level of unpaid labor of residents. The U.S. government investigates citizens' daily 


\section{International Journal of Social Science and Economic Research}

ISSN: $2455-8834$

Volume:06, Issue:03 "March 2021"

time use in order to know the living conditions of residents. With further development of the research, the survey of residents' time use is getting closer to life and work. Samples of different gender, age and race are collected to reflect residents' quality of life. And based on these samples policies can be formulated to ease or solve the relevant social contradictions. Richard seller, winner of the Nobel Prize in economics in 2017, believes that modern social economy should transition from the era of Adam Smith's "economic rational man" to the era of "economic humanization". Human beings are so complex that they should not be driven by interests all the time, but sometimes deviate from the traditional economic hypothesis and care for social welfare, fairness and justice even with the cost to sacrifice their own interests. The concern about people's unpaid labor takes its root from the modern economic background.

In the first volume of Capital, Marx emphasized that capital has the right to control unpaid labor, and capitalists exploit surplus value by occupying workers' unpaid labor time. Therefore, unpaid labor in modern economy can be divided into active and passive. Length of residents' unpaid labor time which can be affected by many factors is closely related to residents' quality of life and happiness. For this reason, the unpaid working hours of residents is mainly taken as a reflection of people's quality of life and social equity. The Organization for Economic Cooperation and Development (OECD) adds the unpaid work time of residents to leisure and personal care time to reflect the better living standard of residents.

In recent years, the theory and research of unpaid labor of residents have expanded from developed countries to developing countries. In China, in 2008, the survey of residents' time was first organized and launched by the National Bureau of statistics, covering more than 10 provinces and autonomous regions, with a total of tens of thousands of survey samples. The "China general social survey" conducted by Renmin University of China also takes residents' leisure time utilization as an important survey item. Since then, provinces and autonomous regions have also spontaneously organized some surveys on the use of residents' living time to reflect the living conditions of residents. The above survey has greatly enriched the samples and types of unpaid labor data of Chinese residents.

At present, the research on unpaid labor is mainly manifested in two aspects:

One is the research on the influencing factors of residents' unpaid labor time, represented by Marc Frenette (2011) and Moses K. muriithi (2017). Marc Frenette finds that the unpaid working time of residents is related to the family composition, especially the number of children in a family. If the number of children increases the unpaid working time of residents will be significantly lengthened. Moses K. muriithi reveals that the unpaid working time of residents is related to their age and gender, and the unpaid working time of women is higher than that of 


\section{International Journal of Social Science and Economic Research}

ISSN: $2455-8834$

Volume:06, Issue:03 "March 2021"

men, which may be explained that women are more patient in doing housework and taking care of children. In China, based on the analysis of the time utilization of urban and rural residents in China, WangQiyan(2000) finds that the unpaid working time of rural residents is significantly higher than that of urban residents.

The other is to reflect the quality of residents' living standard and social equity by their unpaid working hours. Katarina Boye (2009) conducted a survey on different families in 25 European countries. The study found that men's happiness will not be increased by the increase of unpaid working hours, while women's happiness will be increased by the increase of unpaid working hours. However, with the further increase of unpaid working hours, women's happiness will also decrease. Magaña Irene (2018) believes that in high-income countries, unpaid working time has a greater impact on women's well-being, and heavy housework will cause greater psychological burden on women. According to NityaRao (2018), Asian women work more unpaid hours than men, which is mainly due to women's low social status and other unfair social phenomena.

\section{MATERIALS AND METHODS}

This paper uses the data of China Comprehensive Social Survey (CGSS) in 2015. CGSS began in 2003. It is a comprehensive and continuous academic survey project in China. The data have a large sample size, a wide coverage, and the data obtained are reliable. The annual data of CGSS 2015 is the latest survey data released which contains the data of residents' daily time use. The survey covers 10968 residents in 125 districts (counties) of 28 provinces (autonomous regions and municipalities directly under the central government) (Tibet, Xinjiang, Hainan, Hong Kong, Macao and Taiwan are not included). The survey contents include the basic information of the interviewees and their parents, educational career experience and growth information, etc.

We take unpaid household labor time as dependent variable, gender equality attitude, region, marital status, education years, physiological and mental health status and gender as independent variable, age as control variables. Multivariate regression was used to study which factors affect the time of unpaid labor. The descriptive statistics of each variable are shown in table 2, and the explanations of each variable are as follows:

\section{Housework time}

Cgss2015 includes such questions as "how much time do you spend doing housework - hours on weekdays", "how much time do you spend doing housework - minutes on weekdays", "how much time do you spend doing housework - hours on weekends" and "how much time do you spend doing housework - minutes on weekends". This paper takes minutes as the statistical unit, and first calculates the weekdays and weekdays The average time of doing housework is 
calculated as follows:

etime $=($ weektime $\times 5+$ weekendtime $\times 2) / 7$.

In this formula "etime" refers to the average minute one do unpaid housework every day. "weektime" refers to the answer on "how much time do you spend doing housework on weekdays"."weekendtime" refers to the answer on "how much time do you spend doing housework on weekends". If the weekday data or weekend data are missing, the existing data will be replaced.

\section{Gender attitude}

Gender attitude reflects the residents' understanding and recognition of the concept of gender equality. In cgss2015, "do you agree that men are career oriented and women are family oriented?" "Do you agree that men are born stronger than women?" "Do you agree that it's better to marry than to do well?" "Do you agree that female employees should be fired first in the economic downturn?" "Do you agree that husband and wife should share the housework equally?" which constitute a group of gender cognitive problems, the score reflects the individual's gender attitude. The higher the score of the first four questions is, the stronger the unequal attitude towards gender is. On the contrary, the higher the score of the fifth question is, the stronger the unequal attitude towards gender is. The higher is the final score, the stronger is the gender inequality attitude.

\section{Gender}

The difference of unpaid working hours caused by different genders reflects the current social problems in China, such as gender equality, social equity and so on. In China, there has always been a tradition that "women take care of house staff while men take care of work", so women's unpaid work hours are often longer than men.

\section{Health status}

Cgss2017 asked "what do you think of your current health status" and "how often did you feel depressed or depressed in the past four weeks?". In this paper, these two questions represent the physical and mental health of the interviewees respectively.

\section{Region}

Affected by the economic and cultural level, there are obvious differences in the heavy degree of housework in different areas. It is generally believed that residents in economically 


\section{International Journal of Social Science and Economic Research}

ISSN: $2455-8834$

Volume:06, Issue:03 "March 2021"

underdeveloped areas tend to participate in housework personally. Based on the interview location in cgss2017 and the classification of the National Bureau of statistics, this paper divides the interviewees into three regions: East, middle and West. The eastern region is Beijing, Tianjin, Hebei, Liaoning, Shanghai, Jiangsu, Zhejiang, Fujian, Shandong, Guangdong and Hainan; the central region is Shanxi, Jilin, Heilongjiang, Anhui, Jiangxi, Henan, Hubei and Hunan; the western region is Inner Mongolia, Guangxi, Chongqing, Sichuan, Guizhou, Yunnan, Tibet, Shaanxi, Gansu, Qinghai, Ningxia and Xinjiang.

\section{Marital status}

Marital status has a particularly significant impact on women's housework time, The description of marital status in cgss2015 includes unmarried, cohabitation, first marriage with spouse, remarriage with spouse, separation without divorce, divorce and widowhood. In this paper, unmarried, divorced and widowed are classified as having no spouse, while cohabitation, first marriage with spouse and remarriage with spouse are classified as having spouse.

\section{Years of Education}

Attitudes toward unpaid labor may be different among residents with different education levels. Generally speaking, uneducated residents will engage in more unpaid work, and better educated residents may try to reduce their own unpaid work time. This paper deals with the existing question "your current highest education level" in the cgss2015 database. There are 14 options, including"no education, private school and literacy class, primary school, junior high school, vocational high school, ordinary high school, technical secondary school, technical school, College (Adult Higher Education), College (Regular Higher Education), undergraduate (Adult Higher Education), undergraduate (formal higher education), graduate and above, and others." In order to reflect the relationship between different degrees, this paper transforms the education level according to the minimum number of years required to complete the corresponding degree. The results are shown in table 1 .

\section{Health status}

\section{Age}

Different age groups of residents are engaged in different types of unpaid labor and their unpaid labor time is also different. For example, in their student period residents spend most of their time in study and do little unpaid work; the elderly will take care of the middle-aged and young family members, and do a small amount of housework; while the young and middle-aged may undertake most of the unpaid work. Therefore, the age composition of residents is an important 
International Journal of Social Science and Economic Research

ISSN: 2455-8834

Volume:06, Issue:03 "March 2021"

factor to study the level of unpaid working time.

\section{RESULTS AND DISSCUSSIONS}

\section{(1) Gender differences in unpaid working hours}

Figure 1 shows that women generally spend more time in unpaid work than men. The median time for men to engage in unpaid housework is 64.43 minutes, about an hour, while the median time for women is 154.29 minutes, 2.5 times that of men. $75 \%$ of men do housework less than 2 hours a day, while only $25 \%$ of women do unpaid work less than 102.86 minutes, and most women do unpaid work less than 240 minutes.

In the extreme value, after removing the abnormal value, the longest unpaid working time of women was 445.71 minutes per day, while that of men was 248.56 minutes. And $25 \%$ of women work 240 minutes a day without pay.

The above data show that there is a big gender difference in the distribution of unpaid labor in the family. Women pay more in unpaid work at home. Next, this paper will discuss which factors affect unpaid labor time.

\section{(2) Influencing factors of unpaid working time of residents}

OLS regression was used for each variable. The multivariable regression shows that gender attitude, gender factors, years of education, age and mental health status have significant influence on the residents' unpaid working time.

Compared with women, men do 80.24 minutes less unpaid work per day. The second influencing factor is age. Age has a significant positive impact on the time of unpaid work. The older the residents are, the more time they spend in unpaid work. For every one-year increase in the age of residents, the less time they spend in unpaid work is 1.02 minutes on average. The possible explanation is that as the residents get older, their social role gradually changes from the recipient of care to the undertaker of care, so the time spent in unpaid family work increases. Gender attitude has a significant positive impact on household labor time investment, and the average unpaid labor time increases by 7.98 minutes for every 1 point increase in gender inequality.

The annual salary of education has a significant negative impact on the unpaid working time of households. Every year of education increases, the unpaid working time decreases by 2.38 minutes. With the increase of years of education, the residents' thinking is more open and their economic strength is stronger. Therefore, the residents are more likely to complete the 


\section{International Journal of Social Science and Economic Research}

ISSN: $2455-8834$

Volume:06, Issue:03 "March 2021"

housework by purchasing labor rather than doing it by themselves, resulting in the reduction of their own unpaid working time. Mental health status has a negative impact on the time of unpaid work. Unpaid work time shorten when frequency of depression increase, the less time of. When the level of depression frequency increase by one level, the time of unpaid work decreased by 5.83 minutes. Results are shown in table 2.

\section{(3) Gender differences in influencing factors of unpaid working time of residents}

By OLS regression, we found that there were significant differences between male and female on unpaid working time. The results show that the influence of region and marriage on the time of unpaid labor participation of both sexes is opposite; age has significant influence on the time of unpaid labor participation of both sexes; gender attitude and mental health status have significant influence on women but no significant influence on men; physical health status has significant influence on men but no significant influence on women.

The influence of regional factors on the time of unpaid labor participation is opposite. Regional factors have a negative impact on men's participation in unpaid labor time. Compared with the western region, men in the central region have 24.7 minutes less unpaid working time per day, while men in the eastern region have 24.55 minutes less. The regional factors have a significant positive impact on women's unpaid labor participation time. Compared with the western region, the daily unpaid working time of women in the central region is 37.26 minutes more, and that in the eastern region is 16.63 minutes more. One possible explanation is that due to the more perfect urban facilities in the eastern and central regions, some heavy manual unpaid housework, such as making a fire and carrying water, originally undertaken by men, are met by public facilities, while the light manual work undertaken by women is not met by public facilities. And with the improvement of living standards, the standard of residents' requirements for family environment is improved as well, resulting in more unpaid working time for women.

Marriage also has the opposite effect on the time of unpaid labor. Marriage has a negative impact on men's participation in unpaid labor. Compared with unmarried men, married men do 26.23 minutes less unpaid housework daily. Marriage has a positive effect on women's participation in unpaid labor. Compared with unmarried women, married women do housework 34.08 minutes more daily. This is in line with the traditional concept of "male dominating the outside and female dominating the inside". Women who enter the marriage assume more responsibility for family care, and naturally assume part or all of the responsibility for the husband's life.

Age has a significant positive effect on the time of unpaid labor of both sexes. With the increase of age, the time of unpaid labor of men increases by 1.61 minutes, and that of women increases by 0.79 minutes. 
Gender attitude and years of education have a significant impact on women's unpaid working time, but have no significant impact on men. When the score of women's concept of gender inequality increased by 1 point, the time of women's participation in unpaid labor increased by 15.63 minutes. For every one-year increase in women's years of education, their unpaid working time decreases by 3.37 minutes. Although the impact is not significant, it can be seen that the stronger the male gender inequality concept, the less time to undertake housework.

In terms of health, physical health status has a significant impact on men's unpaid working time, but not on women; while mental health status has a significant impact on women, but not on men. For men, the better their health condition is, the more time they are engaged in unpaid work at home. For each higher level of health, they will do 4.79 minutes more unpaid housework. For women, mental health status is the main health factor affecting their unpaid working hours. Every increase in the frequency of depression or depression of women will reduce their unpaid working hours by 7.97 minutes. Results are shown in table 3.

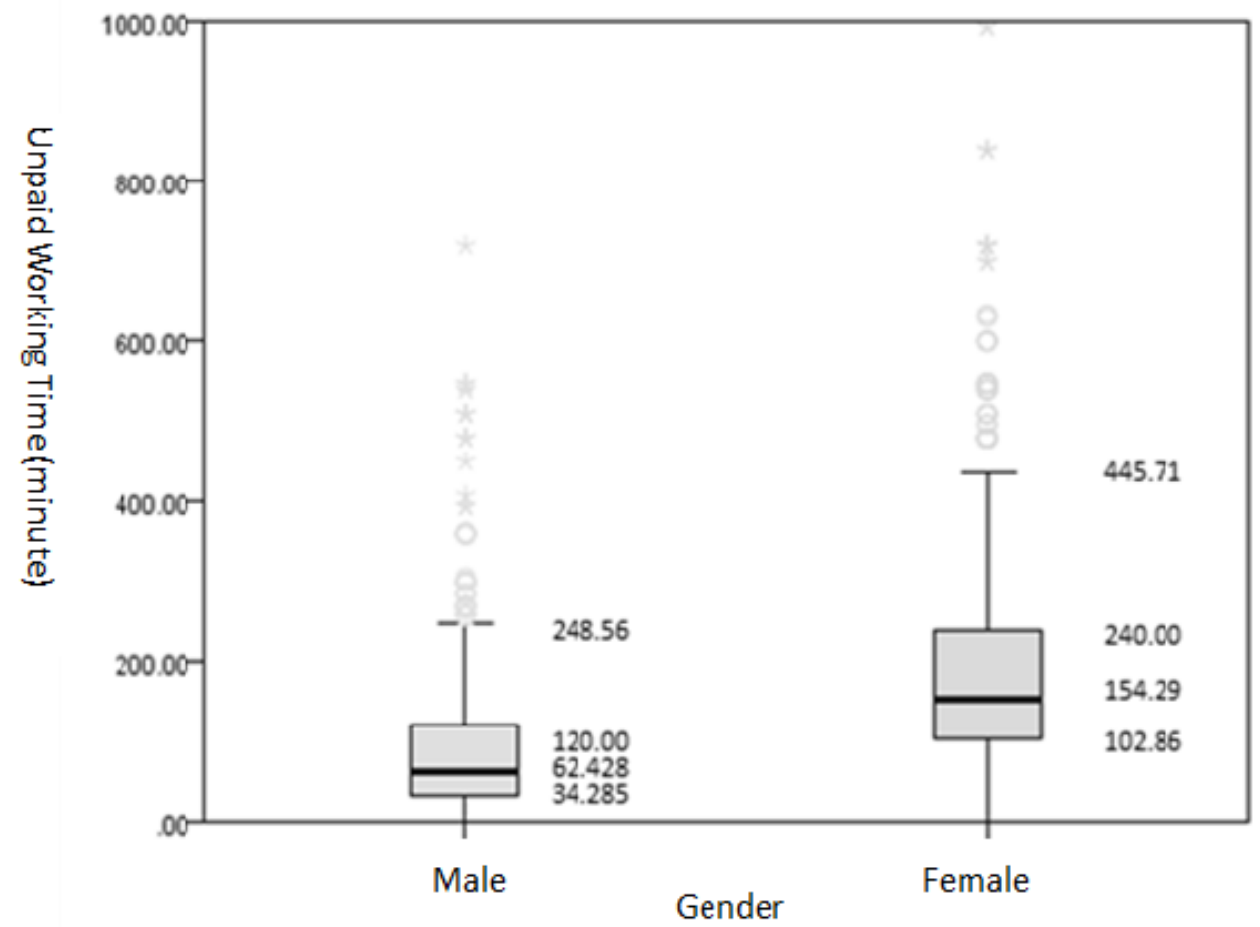

Figure 1 Gender differences in unpaid working hours 
Table1 Conversion table of educational background and years of Education

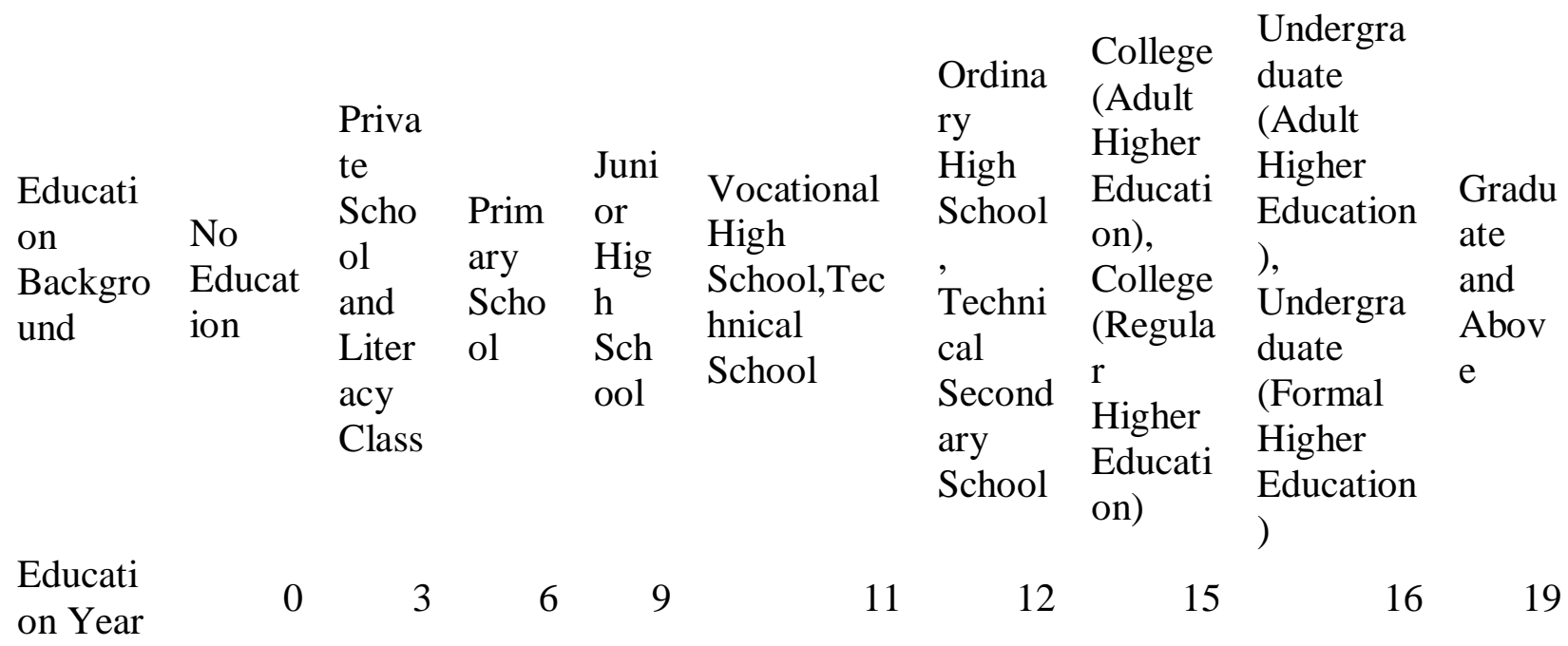

Table2 Regression analysis on Influencing Factors of unpaid working time of residents

\begin{tabular}{lll}
\hline Model & $\begin{array}{l}\text { Nonstandardized } \\
\text { coefficient }\end{array}$ & $\begin{array}{l}\text { Standardization } \\
\text { coefficient }\end{array}$ \\
\hline (constant) & $126.9(19.89)^{* * *}$ & \\
$\begin{array}{l}\text { Gender attitudes } \\
\text { Region(East @ West) }\end{array}$ & $\begin{array}{l}7.98(3.51)^{*} \\
\text { Region(central @ } \\
\text { western) }\end{array}$ & $0.046^{*}$ \\
$\begin{array}{l}\text { Gender(male @ } \\
\text { female) }\end{array}$ & $9.61(5.92)$ & -0.01 \\
marriage & $-80.24(4.8)^{* * *}$ & $-0.337^{* * *}$ \\
Years of Education & $-2.38(0.6)^{* * *}$ & $-0.095^{* * *}$ \\
Health status & $0.76(2.33)$ & 0.007 \\
Mental health status & $-5.83(2.77)^{*}$ & $-0.045^{*}$ \\
Age & $1.02(0.16)^{* * *}$ & $0.140^{* * *}$ \\
Adjusted R-square & 0.89 & \\
\hline
\end{tabular}


International Journal of Social Science and Economic Research

ISSN: 2455-8834

Volume:06, Issue:03 "March 2021"

Dependent variable: housework time $* * * \mathrm{p}<0.001 * * \mathrm{p}<0.01$

$* \mathrm{p}<0.05$

Table3 Influencing factors of unpaid working time regressed according to gender

\begin{tabular}{lll}
\hline Model & Male & Female \\
\hline constant) & $52.8(24.77)^{*}$ & $105.41(30.27)^{* * *}$ \\
Gender attitudes & $-4.88(4.31)$ & $15.63(5.22)^{* * *}$ \\
Region(East @ West) & $-24.55(7.48)^{* * *}$ & $16.63(9.09)^{*}$ \\
Region(central @ & $-24.7(7.26)^{* * *}$ & $37.26(8.79)^{* * *}$ \\
western) & $-26.23(7.49)^{* * *}$ & $34.08(8.58)^{* * *}$ \\
marriage & $-0.06(0.77)$ & $-3.37(0.88)^{* * *}$ \\
Years of Education & $4.79(2.76)^{*}$ & $-1.92(3.55)$ \\
Health status & $-3(3.37)$ & $-7.97(4.14)^{*}$ \\
Mental health status & $1.61(0.19)^{* * *}$ & $0.79(0.26)^{* * *}$ \\
Age & 0.90 & 0.94 \\
Adjusted R-square & &
\end{tabular}

Dependent variable: housework time ${ }^{* * *} \mathrm{p}<0.001 * * \mathrm{p}<0.01 * \mathrm{p}<0.05$

\section{CONCLUTIONS}

In this paper three significant findings are found. First, there is a significant gender difference in the distribution of unpaid labor time within the family. Women spend more time in unpaid labor than men on the whole. Second, from the perspective of all members, the unpaid working time of residents is affected by gender factors, gender attitude, years of education, age and mental health status. Third, there are significant differences in the factors that affect the time of unpaid labor participation between men and women, and the effects are different. For men, compared with the western region, men in the eastern and central regions have less time to participate in family unpaid work; men who enter into marriage have less time to participate in family unpaid work than men who do not enter marriage; the better their health, the more time they spend in family 
International Journal of Social Science and Economic Research

ISSN: 2455-8834

Volume:06, Issue:03 "March 2021"

unpaid work; with the increase of age, the longer they spend in family unpaid work. For women, compared with the western region, women in the eastern and central regions spend more time in unpaid family work; women in marriage spend more time in unpaid family work than women without marriage; the more their mental health is, the more time they spend in unpaid family work; with the increase of age, women spend more time in unpaid family work.

\section{REFERENCE}

Locay, D. L., 1992, Papers and proceedings of the hundred and fourth annual meeting of the American economic association || specialization, household production, and the measurement of economic growth.American Economic Review.82 (2), 399-403.

Frenette, M.,2011, How does the stork delegate work? Childbearing and the gender division of paid and unpaid labour.Journal of Population Economics.24(3), 895-910.

Muriithi, M. K. ,Mutegi, R. G. , \&Mwabu, G. ,2017, Counting unpaid work in kenya: gender and age profiles of hours worked and imputed wage incomes. Journal of the Economics of Ageing.S2212828X16300706.

Wang,Q.Y.,2000,Analysis on the distribution of life time of urban residents in China.Sociological Studies.(04),86-97.

Boye, K., 2009, Relatively different? How do gender differences in well-being depend on paid and unpaid work in Europe? Social Indicators Research. 93(3), 509-525.

Magaña I, Martínez P, Loyola MS., 2018,Health outcomes of unpaid care workers in low-income and middle-income countries: a protocol for a systematic review. BMJ Open. Jan;8(1):e018643.

Rao, N.,2018, Global agendas, local norms: mobilizing around unpaid care and domestic work in Asia. Development \&Change.49(3), 735-758. 